\title{
The Internationalisation of the Academy: Convergence and Divergence across Disciplines
}

\author{
MICHELE ROSTAN and FLAVIO ANTONIO CERAVOLO \\ Centre for Study and Research on Higher Education Systems, University of Pavia, \\ Strada Nuova 65, 27100 Pavia, Italy. E-mail: michele.rostan@unipv.it; \\ flavioantonio.ceravolo@unipv.it
}

\begin{abstract}
The internationalisation of the academy varies according to individual, institutional and structural characteristics. Among factors influencing it, discipline plays a major role. Relying on data collected by two international comparative studies - the Changing Academic Profession Study and the Academic Profession in Europe Study - this article focuses on two aspects of the internationalisation of the academy - namely, international research collaboration and international mobility - asking whether these two aspects are associated with academic disciplines and how. Results from multivariate data analyses comparing Europe and the Rest of the World or other meaningful macro-regions - show that in some areas, such as international research collaboration and educational circulation, the international behaviours of academics belonging to different disciplines diverge, while in some others, such as research productivity related to international research collaboration and short-term professional circulation, they converge.
\end{abstract}

\section{Introduction}

It is customary to distinguish three main aspects of the internationalisation of the academy: international teaching, international research, and international mobility. Each of these domains includes a plurality of activities. International teaching includes various accomplishments such as integrating an international perspective or content in courses, teaching international students at your home institution, teaching in a language different from the language of instruction currently employed at the home institution, primarily employing English as a second language in teaching, and teaching courses abroad. International research includes characterising one's own primary research as international in scope or orientation, collaborating with international colleagues in 
research efforts, primarily employing English in research as a second language, and obtaining funding for research from international organisations. International research is connected to international dissemination, i.e. publishing in a language different from the language of instruction currently employed at the home institution, publishing in a foreign country, and co-authoring a publication with colleagues located in other countries. Finally, international mobility refers to diverse actions such as earning a degree abroad, especially an advanced degree, travelling for professional purposes, and moving to another country to get a job. Some of these international academic activities entail the crossing of state borders while others occur 'at home'.

When we aim at investigating all these aspects and activities, and especially when we aim at studying the relationship between some basic features of the academic profession, namely the rank or position of individual academics, the type of institution they work at, their discipline - not to speak of their education and career path - we may run into some problems.

First, we may lack the information we need simply because data are not available. Second, data may be available but their scope may be limited, that is available information may not encompass all the dimensions, aspects, characteristics of the academic profession we are interested in. This is especially the case when we are interested in the links between the scientific field in which the individual academic is active and other aspects of her or his career and work. Third, data may be available but only for one country or a limited number of countries, thus hindering international comparisons.

Some of these problems may be addressed through large-scale international surveys. Although these instruments have their own limitations, they still provide a valuable source of information that we need to deal with when discussing issues such as the relationships between academic disciplines and the internationalisation of the academy.

\section{The Contribution of Large-scale Comparative Surveys}

In recent times, at least two large-scale international research projects on the academic profession have been carried out. The first is called 'The Changing Academic Profession' and is generally known as 'The CAP Study'. In the frame of this multinational project an international survey was conducted in the year 2007/2008 as a follow-up of a previous survey promoted by the Carnegie Foundation for the Advancement of Teaching in the early 1990s. The survey collected information on about 25,000 academics working in 18 countries and the Special Administrative Region of Hong Kong. The international sample included academics from countries located in different continents: seven in Europe, one in Africa, five in Asia, one in Oceania, three in North America and two in South America. ${ }^{1,2}$

The second project is called 'The Academic Profession in Europe: Responses to Societal Challenges', also known as 'The EUROAC Project'. Within this project, in the year 2010 an international survey was carried out in five countries - Austria, Croatia, Ireland, Poland, and Switzerland - collecting information from about 8000 academics. $^{3,4}$ 
The two surveys were based on the same instrument, an almost identical questionnaire addressing a common set of issues: teaching and research activities, career history and mobility, demographic background, including citizenship and education. They also collected valuable information on the international dimension of the academic profession. ${ }^{5}$

As a consequence, the two surveys provide an estimate of the extent to which the academic profession is internationalised at the beginning of the 21 st century. Among the most internationalised aspects of the academic profession we find the internationalisation of the contents of teaching and research, as most academics 'integrate international perspectives into their courses' and consider their primary research as 'international in scope or orientation'. Next there is the dissemination of knowledge in terms of publishing in a foreign country or in a foreign language, and finally international research collaboration, that is collaborating with international colleagues in research efforts. Among the least internationalised activities we find teaching in a foreign language and teaching abroad.

The two surveys also provide the opportunity to investigate the relationship among a wide range of dimensions of the academic profession, including international teaching, international research and international mobility. In this article, we focus on two aspects of the internationalisation of the academy - namely international research collaboration and international mobility - asking whether these two aspects are associated with academic disciplines and how.

\section{Convergence or Divergence in International Activities?}

The possible convergence or divergence of the internationalisation of the academy across disciplines can be analysed relying on the information collected by the two mentioned surveys. Let us ask two questions. First, does the fact of belonging to a discipline make a difference in academics' involvement in international research networks? If it does, we can assume that a divergence emerges across disciplines in international research collaboration; if it does not, we can assume that a convergence is there. Second, does the fact of belonging to a discipline make a difference in academics' international mobility? Again, if it does, we can assume that a divergence emerges across disciplines; if it does not, we can assume that a convergence is there.

As we are interested in the impact of discipline on international research collaboration and international mobility - or, at least, in the association between discipline and these two aspects of the academic profession - we organise academic disciplines into five categories following the International Standard Classification of Education (ISCED).

(1) Teacher training and education sciences and humanities and arts.

(2) Social and behavioural sciences, business and administration, economics, and law.

(3) Life sciences, physical sciences, mathematics, computer sciences, and agriculture. 
(4) Engineering, manufacturing, construction, and architecture.

(5) Medical sciences, health-related sciences, and social services.

In the following, we shall mostly refer to these categories as 'humanities', 'social sciences', 'science', 'engineering', and 'medical sciences'. The reader should keep in mind, though, the whole range of disciplines merged within an individual category.

\section{International Research Collaboration in Europe}

We start by looking at international research collaboration in the European context. In the 12 European countries participating in the CAP and EUROAC surveys, most academics active in research do collaborate with international colleagues $(62 \%)$. International research collaboration is more frequent among academics from science $(72 \%)$, less frequent among academics from humanities, social sciences and engineering (56-57\%), with those from the medical sciences in between $(62 \%)$.

We cannot assume, though, that international research collaboration depends only on discipline. Thus, in order to investigate the relationship between discipline and international research collaboration, we must take into account other factors possibly influencing it. ${ }^{6}$ Relevant factors may be gathered into three groups:

- individual biographical features both ascribed and acquired, such as gender, age, family background and education;

- organisational and professional factors linked to the type of institution academics work at, their expertise (discipline, English proficiency, the emphasis or orientation of research activities along the basic-applied continuum) and career stage (academic rank);

- structural features characterising the wider context within which research activities are performed, such as country characteristics: population, wealth, and language.

Thanks to a multivariate model it is possible to analyse the effect of discipline on international research collaboration - or the association between the two - net of the influence of all the other relevant factors.

The multivariate analysis of data collected by the CAP and the EUROAC surveys in the 12 mentioned European countries yields the following results (Table 1): compared with academics belonging to the social sciences, academics from - on the one hand - the humanities, and - on the other hand - from science are more likely to collaborate with international colleagues in research. Engineers and architects, and medical academics are not statistically different from social scientists, and academics from business or law schools, in their involvement in international research networks.

Results also provide information on the effect of each relevant factor on international research collaboration all other things being equal. Academic males are more likely to collaborate with international colleagues than females. Middle-aged academics - especially people in their $40 \mathrm{~s}$ and $50 \mathrm{~s}$ - are more likely to collaborate than younger academics. Parents' education doesn't have an impact. Holding a 
Table 1. Predictors of international research collaboration: comparing Europe and the Rest of the World (binomial regression's estimates)

\begin{tabular}{|c|c|c|c|c|}
\hline & \multicolumn{2}{|c|}{ European countries } & \multicolumn{2}{|c|}{ Rest of the World } \\
\hline & $B$ & S.E. & $B$ & S.E. \\
\hline Intercept & $-1.010^{* * *}$ & 0.142 & $-1.546 * * *$ & 0.139 \\
\hline Total population (millions) & $-0.012 * * *$ & 0.001 & $-0.001 * * *$ & 0.000 \\
\hline GDP Per capita. PPP (constant 2005, International \$, Thousands) & $.021 * * *$ & 0.003 & $-0.008 * *$ & 0.003 \\
\hline \multicolumn{5}{|l|}{ Gender } \\
\hline Male & $0.333 * * *$ & 0.049 & $0.194 * *$ & 0.054 \\
\hline Female & 0 & & 0 & \\
\hline \multicolumn{5}{|l|}{ Age cohort } \\
\hline Born up to 1950 & -0.086 & 0.086 & $-0.244^{*}$ & 0.094 \\
\hline Born 1951-1960 & $0.145^{* *}$ & 0.075 & -0.070 & 0.081 \\
\hline Born 1961-1970 & $0.246 * * *$ & 0.063 & -0.043 & 0.073 \\
\hline Born 1971 and after & 0 & & 0 & \\
\hline \multicolumn{5}{|l|}{ Highest degree } \\
\hline First Degree & $-0.951 * * *$ & 0.087 & $-0.675 * * *$ & 0.112 \\
\hline Second Degree & $-10.185 * * *$ & 0.099 & $-0.858 * * *$ & 0.094 \\
\hline Doctoral degree & $-0.514 * * *$ & 0.067 & -0.017 & 0.069 \\
\hline Postdoctoral degree & 0 & & 0 & \\
\hline \multicolumn{5}{|l|}{ Primarily employing English as lingua franca in research } \\
\hline Yes (as mother tongue) & $0.950 * * *$ & 0.179 & $0.515 * * *$ & 0.091 \\
\hline Yes (as second language) & $0.993 * * *$ & 0.052 & $0.357 * * *$ & 0.066 \\
\hline No & 0 & & 0 & \\
\hline \multicolumn{5}{|l|}{ Parents' Education } \\
\hline Parents with tertiary education & $0.083^{*}$ & 0.046 & $0.103 * *$ & 0.050 \\
\hline Parents without tertiary education & 0 & & 0 & \\
\hline \multicolumn{5}{|l|}{ Doctoral and-or postdoctoral degree earned abroad } \\
\hline Yes & $0.589 * * *$ & 0.088 & $0.669 * * *$ & 0.064 \\
\hline No & 0 & & 0 & \\
\hline \multicolumn{5}{|l|}{ Academic rank } \\
\hline Senior position & $0.416^{* * *}$ & 0.062 & $0.401 * * *$ & 0.059 \\
\hline Junior/other position & 0 & & 0 & \\
\hline \multicolumn{5}{|l|}{ Type of institution } \\
\hline Universities & $0.534 * * *$ & 0.075 & $0.914 * * *$ & 0.063 \\
\hline Other Institutions & 0 & & 0 & \\
\hline \multicolumn{5}{|l|}{ Discipline of current academic unit } \\
\hline Education \& humanities, & $0.220 * *$ & 0.073 & $-0.158 * *$ & 0.072 \\
\hline Science & $0.523 * * *$ & 0.068 & $0.391 * * *$ & 0.071 \\
\hline Engineering and others & 0.076 & 0.077 & 0.088 & 0.080 \\
\hline Medical \& health sciences & 0.139 & 0.087 & $0.255^{* *}$ & 0.083 \\
\hline Social sciences, business \& law & 0 & & 0 & \\
\hline \multicolumn{5}{|l|}{ Research emphasis: basic vs applied } \\
\hline Basic & 0.079 & 0.054 & $0.194 * * *$ & 0.059 \\
\hline Combined & $0.119^{*}$ & 0.064 & $0.143 * *$ & 0.060 \\
\hline Applied & 0 & & 0 & \\
\hline \multicolumn{5}{|l|}{ Language (English used in the country) } \\
\hline Yes, either as main or one of the official languages & $-0.309 *$ & 0.173 & $0.165^{* *}$ & 0.085 \\
\hline No & 0 & & 0 & \\
\hline
\end{tabular}

${ }^{*} P>0.10 ; * * P>0.05 ; * * * P>0.01$

Source: CAP Study and EUROAC Project data.

Note: Europe includes Austria, Croatia, Finland, Germany, Ireland, Italy, The Netherlands, Norway, Poland, Portugal, Switzerland, and The United Kingdom; The Rest of the World includes Argentina, Australia, Brazil, Canada, China, Hong Kong (SAR), Japan, Republic of Korea, Malaysia, Mexico, South Africa, and United States of America. 
post-doctoral degree and having earned a postdoc and/or a doctoral degree abroad both increase the likelihood of collaborating internationally. Academics working at universities are more likely to collaborate than their colleagues working at other institutions of higher education, and those holding a senior position are more likely to collaborate than junior academics. Primarily employing English in research activities - either as the mother tongue or as the second language - is strongly associated with international research collaboration while research emphasis - either basic, applied or combined - does not have an influence. Finally, working in small countries, and working in wealthier countries increases the likelihood of collaborating internationally, while a country's language tradition does not have an influence.

\section{International Research Collaboration in the Rest of the World}

Thanks to the CAP Study, the European situation can be compared to the situation of the Rest of the World. Outside Europe, international research collaboration is less frequent: only $34 \%$ of the surveyed academics in 12 non-European countries say that they collaborate with international colleagues in research. International research collaboration is more frequent among academics from science and medical sciences (39-40\%), less frequent among academics from both humanities and engineering $(29-30 \%)$, with those from the social sciences in between $(40 \%)$.

The same model of multivariate analysis that has been used for European data can be applied to analyse non-European data in order to assess the influence of discipline on international collaboration net of all other factors (Table 1). The results of this analysis show that compared with academics belonging to the social sciences, academics from the humanities are less likely to collaborate with international colleagues in research, while academics from the natural and the medical sciences are more likely to collaborate internationally. Further, engineers and architects are not statistically different from social scientists and academics from business or law schools.

Again, the multivariate model also provides information on the net effect of each relevant characteristic. Academic males are more likely to collaborate internationally than females. Academics belonging to the oldest age group - people aged 60 or more are less likely to collaborate than those belonging to the youngest group. Academics with parents with tertiary education are more likely to collaborate internationally than their peers whose parents have a lower level of educational attainment. Holding a post-doctoral and/or a doctoral degree, and having earned a postdoc and/or a doctoral degree abroad both increase the likelihood of collaborating internationally. Academics working at universities are more likely to collaborate with international colleagues than those working at other institutions of higher education, and seniors are more likely to do so than juniors. Research characteristics have an impact as well. Primarily employing English in research - either as the mother tongue or as the other language - increases the likelihood of collaborating internationally. Academics engaged in basic or combined research are more likely to collaborate than 
those focusing on applied research. Finally, working in small countries increases the likelihood of collaborating with international colleagues, while working in wealthier countries decreases it, and a country's language tradition does not have an influence.

\section{Comparing Europe and the Rest}

The results from the two models allow us to compare the impact of discipline on international research collaboration - or the association between the two - in Europe and in the Rest of the World.

Disciplines have an impact on academics' international research collaboration worldwide. Thus, we can detect a divergence across disciplines in the collaboration with international colleagues in research efforts. But trends are different within or outside of Europe.

In Europe, academics from both the humanities and sciences are more likely to collaborate with international colleagues in research than social scientists, engineers and architects, and academics in the medical sciences. Outside Europe, academics from the humanities are less likely to collaborate with international colleagues than engineers and architects as well as social scientists (including academics from business or law schools); academics from the natural and the medical sciences are even more likely to collaborate internationally.

Consequently, we can arrive at the following conclusions.

- Belonging to the field of natural sciences has the same impact everywhere: scientists are more likely to collaborate internationally than others.

- Belonging to the field of humanities has an opposite effect: among Europeans the international collaboration is relatively high, while among those outside Europe it is relatively low.

- Medical scientists display a different behaviour within or outside Europe: they are more likely to collaborate internationally when working and living in non-European countries, while they do not differ from the average of disciplines in the European countries.

To sum up, when collaboration in research with international colleagues is at stake, academics belonging to different disciplines display a divergent behaviour. This happens all over the world but in different ways.

\section{Research Productivity}

Research collaboration with international colleagues is not only shaped by a complex set of factors but in turn may be understood as shaping other aspects of the academic profession. One of the most relevant aspects of it concerns academics' research productivity.

Again, data collected through the CAP study and the EUROAC project provide the opportunity to check whether there are differences across disciplines in the 
influence of international research collaboration on productivity. ${ }^{7}$ Both surveys have asked respondents how many scholarly contributions they have completed in the three years before the survey was carried out. Ten products were considered: authored or co-authored scholarly books, edited or co-edited scholarly books, articles published in an academic book or journal, research report/monograph written for a funded project, paper presented at a scholarly conference, professional article written for a newspaper or magazine, patent secured on a process or invention, computer program written for public use, artistic work performed or exhibited, and video or film produced.

Here we focus only on a single category, namely 'articles published in academic books or journals'. This item - possibly together with papers presented at a conference - seems to be best suited to account for the different styles or habitus of publication that are customary across disciplines, as both contributions in journals, likely more frequent within the 'hard' sciences, and contributions in books, likely more frequent in the 'soft' sciences, are included.

Again, we shall first look at the influence of international research collaboration on productivity across disciplines within Europe, and then outside Europe. Table 2 shows the results of a one-way between subjects ANOVA comparing the effect of international collaboration on the publication rates of faculty in the five alreadymentioned disciplinary categories within selected European countries.

It can be noted that collaborating with international colleagues in research increases the average number of articles published in a three-year period across all the disciplinary groups, although to a greater extent within the 'hard' sciences. We can conclude that collaborating with international colleagues has a positive impact on academics' productivity as measured through the number of articles published in scholarly books or journals, ${ }^{8}$ and that this holds true across all disciplines.

A very similar relationship occurs outside Europe as well. As shown in Table 2, academics collaborating with international colleagues publish more articles than those who do not collaborate. This happens across all disciplinary groups and the strength of the relationship appears to be identical across disciplines.

Comparing Europe and the rest of the world, we can conclude that international research collaboration and research productivity are strictly associated across all disciplines worldwide, although this association is stronger for 'hard' disciplines in Europe. In other words, a convergence across disciplines emerges in the relationship between international research collaboration and productivity.

\section{International Academic Mobility}

The CAP survey gives us also the opportunity to investigate the differences in international academic mobility across disciplines. ${ }^{9-11}$ The survey collected a host of information on several aspects of academics' education and career providing the opportunity to create a typology of international mobility throughout the entire life course of the interviewed academics. The typology includes six types of mobility. 
Table 2. Articles published in an academic book or journal by international collaboration and discipline: comparing Europe and the Rest of the World (mean, standard deviation, standard error, yes/no ratio)

Europe

N Mean St. dev. $\quad$ S.E. $\quad \begin{aligned} & \text { Lower bound } \quad \text { Upper bound } \\ & \text { Yes/No ratio }\end{aligned}$

Education \& humanities

$\begin{array}{llllllll}\text { Yes } & 1490 & 6.18 & 8.102 & 0.210 & 5.76 & 6.59 & 1.6 \\ \text { No } & 1102 & 3.84 & 5.197 & 0.157 & 3.53 & 4.15 & \end{array}$

Social sciences, business \& law

$\begin{array}{crrrrrrr}\text { Yes } & 1524 & 6.53 & 7.645 & 0.196 & 6.15 & 6.92 & 1.7 \\ \text { No } & 1122 & 3.77 & 5.421 & 0.162 & 3.45 & 4.09 & \\ \text { Science } & & & & & & & \\ \text { Yes } & 2952 & 7.67 & 10.038 & 0.185 & 7.31 & 8.04 & 2.3 \\ \text { No } & 1091 & 3.38 & 4.676 & 0.142 & 3.11 & 3.66 & \end{array}$

Engineering, manufacturing, construction $\&$ architecture

\begin{tabular}{lrrrrrrrr} 
Yes & 1261 & 6.67 & 11.427 & 0.322 & 6.04 & 7.30 & 2.2 \\
No & 909 & 3.06 & 5.160 & 0.171 & 2.73 & 3.40 & \\
Medical sciences, health related sciences \& social services & & \\
Yes & 968 & 10.19 & 12.626 & 0.406 & 9.40 & 10.99 & 2.2 \\
No & 573 & 4.73 & 5.857 & 0.245 & 4.25 & 5.22 & \\
\hline
\end{tabular}

Rest of the World

\begin{tabular}{|c|c|c|c|c|c|}
\hline & & & $95 \%$ confidenc & terval for mean & \\
\hline Mean & St. dev. & S.E. & Lower bound & Upper bound & Yes/No ratio \\
\hline
\end{tabular}

Education \& humanities

$\begin{array}{lrrrrrrr}\text { Yes } & 746 & 6.83 & 8.954 & 0.328 & 6.19 & 7.48 & 1.7 \\ \text { No } & 1583 & 4.03 & 4.580 & 0.115 & 3.80 & 4.25 & \end{array}$

Social sciences, business \& law

$\begin{array}{crrrrrrr}\text { Yes } & 811 & 7.12 & 7.468 & 0.262 & 6.61 & 7.64 & 1.7 \\ \text { No } & 1480 & 4.20 & 5.042 & 0.131 & 3.94 & 4.46 & \\ \text { Science } & & & & & & & \\ \text { Yes } & 1010 & 11.08 & 15.791 & 0.497 & 10.11 & 12.06 & 1.7 \\ \text { No } & 1341 & 6.58 & 8.755 & 0.239 & 6.11 & 7.05 & \end{array}$

Engineering, manufacturing, construction $\&$ architecture

\begin{tabular}{lrrrrrrr} 
Yes & 533 & 11.46 & 13.535 & 0.586 & 10.31 & 12.62 & 1.7 \\
No & 1101 & 6.63 & 11.249 & 0.339 & 5.96 & 7.29 & \\
Medical sciences, health related sciences \& social services & & \\
Yes & 563 & 12.44 & 16.773 & 0.707 & 11.05 & 13.82 & 1.8 \\
No & 799 & 6.76 & 10.878 & 0.385 & 6.01 & 7.52 & \\
\hline
\end{tabular}

Source: CAP Study and EUROAC Project data.Note: Europe includes Austria, Croatia, Finland, Germany, Ireland, Italy, The Netherlands, Norway, Poland, Portugal, Switzerland, and The United Kingdom; The Rest of the World includes Argentina, Australia, Brazil, Canada, China, Hong Kong (SAR), Japan, Republic of Korea, Malaysia, Mexico, South Africa, and United States of America. 
The first type includes academics having been born in the country of their current employment, earned all their higher education degrees in their native country, and never spent periods abroad during their career. Thus, we can say that these people never experienced international mobility. This type accounts for $58 \%$ of the CAP international sample.

The second type $(16 \%)$ includes academics who, while being born in the country of current employment, have earned at least one of their higher education degrees abroad. Their experience abroad started early in their life and has had a rather short duration. It was aimed at educational purposes. As this type of mobility entails circulation of academics-to-be across countries' borders, we may refer to it as international educational circulation, and to those involved in it as academics internationally circulating for study.

The third type $(10 \%)$ includes academics who, while being born in the country of current employment and having earned their degrees there, have spent short periods abroad during their career, that is they have stayed in another country for no more than two years, either continuously or not. Their experience abroad started rather late in their life, has had a short duration and has had professional purposes. This type of mobility entails circulation across the borders of the country of current employment, as well. Consequently, we may refer to it as international short-term professional circulation and to academics involved in it as internationally circulating for work spending short periods abroad.

The fourth type $(6 \%)$ is similar to the third one, but overall academics included in it have stayed abroad for more than two years. Consequently, we may refer to it as international long-term professional circulation and to academics involved in it as internationally circulating for work spending long periods abroad.

The fifth type $(6 \%)$ includes academics having been born in a country different from the country of their current employment and having earned all their degrees abroad. These people entered the country of their current employment being fully qualified for a job in higher education. Their experience abroad started late in their life, and it was still ongoing at the time when the survey was carried out. As this type of mobility entails a one-way movement from the country of origin, that is the country of residence at birth, to the country of destination, that is the country of current employment, we may refer to it as international job migration. We can consider academics involved in it as international late migrants for work.

The sixth type $(5 \%)$ includes academics having been born in a country different from the country of their current employment and they moved to it to earn a degree. These people entered the country where they were working at the time of the survey as students. Later on they found a job in higher education. Their experience abroad started quite early in their life and was still continuing at the time when the CAP survey was carried out. Again, this type of mobility entails a one-way movement from the country of origin to the country of destination. Therefore, we may refer to it as educational early migration, and to those involved in it as international early migrants for study. 


\section{Educational and Short-term Professional Circulation}

We shall focus on the two most frequent types of international mobility, namely international educational circulation, or international circulation for study, and international short-term professional circulation.

As it was for international research collaboration, we expect that international mobility varies across disciplines as well. Similarly, we expect that other factors may influence international mobility apart from discipline.

When educational circulation is at stake, among these factors we find:

- Individual biographical characteristics, such as gender, age, and family background;

- Structural features characterising an academic's native country such as size, wealth, language, and cultural and political traditions.

Relying once more on a multivariate model it is possible to investigate the effect of disciplines on international circulation for study purposes - or the association between the two - net of the influence of other relevant factors.

As shown in Table 3, academics-to-be belonging to all disciplines are more likely to study abroad compared with students in the medical sciences. Students in the natural sciences are the most likely to study abroad followed by students in the social sciences, the humanities, and - finally - in engineering and architecture.

As we turn to short-term professional circulation, considering individual characteristics and macro structural factors is not enough and other characteristics pertaining to academics' career and work must be included in the analysis. This is why the multivariate model investigating the determinants of short-term professional circulation includes a broader set of factors than the one addressing educational circulation. These factors include the type of institution in which individuals practice their profession, academic rank, the emphasis of their primary research, either basic or applied, or a combination of both, and their preferences for teaching and research. Two other aspects of academic career and work are also included: whether respondents have earned a postdoctoral and/or a doctoral degree, and whether they primarily employ English - either as their mother tongue or as second language in teaching and/or research.

As shown in Table 4, a host of different factors have a net effect on the likelihood of circulating for work purposes and spending short periods abroad, but these factors do not include academic disciplines. Briefly, academics from different disciplines are equally likely to circulate internationally for professional purposes albeit for short periods.

Comparing the results of the models analysing the two most frequent types of international academic mobility, we conclude that while international educational circulation implies a divergence across disciplines, short-term professional circulation does not show any difference across disciplines, indicating a convergence among them.

Although the results of data analysis on the other types of mobility are not presented here, we can add that educational migration, long-term professional 
Table 3. Factors explaining educational circulation (multinomial regression's estimates)

\begin{tabular}{|c|c|c|}
\hline & $B$ & S.E. \\
\hline Intercept & $-2.836^{* *}$ & 0.107 \\
\hline \multicolumn{3}{|l|}{ English (country of employment) } \\
\hline Exclusively English & $-0.459 * *$ & 0.085 \\
\hline English also & $0.230 * *$ & 0.075 \\
\hline No English & 0 & \\
\hline \multicolumn{3}{|l|}{ Country size } \\
\hline Small & $1.307 * *$ & 0.077 \\
\hline Medium & $0.965 * *$ & 0.069 \\
\hline Large & 0 & \\
\hline \multicolumn{3}{|c|}{ Economic status (country of employment) } \\
\hline Mature & $-0.751 * *$ & 0.064 \\
\hline Emerging & 0 & \\
\hline \multicolumn{3}{|l|}{ Asian country } \\
\hline China & $-1.259 * *$ & 0.116 \\
\hline Other Asian & $1.382 * *$ & 0.061 \\
\hline The rest & 0 & \\
\hline \multicolumn{3}{|l|}{ Gender } \\
\hline Male & $0.239 * *$ & 0.05 \\
\hline Female & 0 & \\
\hline \multicolumn{3}{|l|}{ Age cohort } \\
\hline Born up to 1950 & $0.692 * *$ & 0.079 \\
\hline Born 1951-1960 & $0.687 * *$ & 0.069 \\
\hline Born 1961-1970 & $0.657 * *$ & 0.068 \\
\hline Born 1971 and after & 0 & \\
\hline \multicolumn{3}{|l|}{ Parents' education } \\
\hline Parents with tertiary education & $0.276^{* *}$ & 0.046 \\
\hline Parents without tertiary education & 0 & \\
\hline \multicolumn{3}{|l|}{ Discipline of highest degree } \\
\hline Education \& humanities & $0.282 * *$ & 0.085 \\
\hline Social sciences, business \& law & $0.371 * *$ & 0.084 \\
\hline Science & $0.568 * *$ & 0.083 \\
\hline Engineering and others & $0.215^{* *}$ & 0.091 \\
\hline Medical \& health sciences & 0 & \\
\hline
\end{tabular}

$* * P>0.05$

Source: CAP Study data.

Note: Countries include Finland, Germany, Italy, The Netherlands, Norway, Portugal, The United Kingdom, Argentina, Australia, Brazil, Canada, China, Hong Kong (SAR), Japan, Republic of Korea, Malaysia, Mexico, South Africa, and United States of America.

circulation and job migration are not influenced by discipline. Similar to what happens for short-term professional circulation, in these cases academics from different disciplines appear to behave in the same way. 
Table 4. Factors explaining short-term professional circulation (multinomial regression's estimates)

\begin{tabular}{|c|c|c|}
\hline & $B$ & S.E. \\
\hline Intercept & $-3.179 * *$ & 0.176 \\
\hline \multicolumn{3}{|l|}{ English (country of employment) } \\
\hline Exclusively English & $-0.570^{* *}$ & 0.153 \\
\hline English also & $-0.485 * *$ & 0.126 \\
\hline No English & 0 & \\
\hline \multicolumn{3}{|l|}{ Country size } \\
\hline Small & 0.093 & 0.107 \\
\hline Medium & 0.050 & 0.090 \\
\hline Large & 0 & \\
\hline \multicolumn{3}{|c|}{ Economic status (country of employment) } \\
\hline Mature & $0.474 * *$ & 0.101 \\
\hline Emerging & 0 & \\
\hline \multicolumn{3}{|l|}{ Asian country } \\
\hline China & $-0.710 * *$ & 0.140 \\
\hline Other Asian & $0.352 * *$ & 0.098 \\
\hline The rest & 0 & \\
\hline \multicolumn{3}{|l|}{ Gender } \\
\hline Male & 0.066 & 0.066 \\
\hline Female & 0 & \\
\hline \multicolumn{3}{|l|}{ Age cohort } \\
\hline Born up to 1950 & $0.530 * *$ & 0.113 \\
\hline Born 1951-1960 & $0.358 * *$ & 0.103 \\
\hline Born 1961-1970 & $0.439^{* *}$ & 0.092 \\
\hline Born 1971 and after & 0 & \\
\hline \multicolumn{3}{|l|}{ Parents' education } \\
\hline Parents with tertiary education & $0.213^{* *}$ & 0.059 \\
\hline Parents without tertiary education & 0 & \\
\hline \multicolumn{3}{|l|}{ Doctoral or postdoctoral degree } \\
\hline Yes & $0.578 * *$ & 0.071 \\
\hline No & 0 & \\
\hline \multicolumn{3}{|l|}{ Type of institution } \\
\hline Universities & $0.413^{* *}$ & 0.086 \\
\hline Other institutions & 0 & \\
\hline \multicolumn{3}{|l|}{ Academic rank } \\
\hline Senior position & $0.412 * *$ & 0.073 \\
\hline Junior/other position & 0 & \\
\hline \multicolumn{3}{|l|}{ Discipline of teaching } \\
\hline Education \& humanities & -0.046 & 0.103 \\
\hline Social sciences, business \& law & -0.067 & 0.099 \\
\hline Science & -0.052 & 0.096 \\
\hline Engineering and others & -0.063 & 0.108 \\
\hline Medical \& health sciences & 0 & \\
\hline \multicolumn{3}{|l|}{ Research emphasis: basic vs. applied } \\
\hline Basic & $0.164 * *$ & 0.069 \\
\hline Combined & 0.038 & 0.075 \\
\hline Applied & 0 & \\
\hline
\end{tabular}


Table 4. (Continued)

\begin{tabular}{llc}
\hline & \multicolumn{1}{c}{$B$} & S.E. \\
\hline Primarily in teaching & $-0.442^{* *}$ & 0.167 \\
In both, but leaning towards teaching & $-0.316^{* *}$ & 0.099 \\
In both, but leaning towards research & -0.072 & 0.087 \\
Primarily in research & 0 & \\
English as lingua franca in teaching and/or research & & 0.157 \\
Yes, as mother tongue & 0.218 & 0.073 \\
Yes, as second tongue & 0.512 & \\
No & 0 & \\
\hline \hline
\end{tabular}

$* * P>0.05$

Source: CAP Study data.

Note: Countries include Finland, Germany, Italy, The Netherlands, Norway, Portugal, The United Kingdom, Argentina, Australia, Brazil, Canada, China, Hong Kong (SAR), Japan, Republic of Korea, Malaysia, Mexico, South Africa, and United States of America.

\section{Conclusions: The Different Role of Disciplines}

The analysis of data provided by two large-scale comparative surveys on the academic profession has given us the possibility to identify two international academic activities in which belonging to a discipline makes the difference, namely international research collaboration and educational circulation. Further, we have also identified two activities in which discipline does not make a difference, namely the influence of international research collaboration on research productivity, and short-term professional circulation. In the first two activities, academics belonging to different disciplines behave in a divergent way in terms of internationalisation, while in the second two activities they behave in a convergent way.

The relationships between discipline and, on the one hand, international research collaboration and, on the other hand, educational circulation, have been controlled by several other factors, which may be associated with these two academic activities. Thus, we can come to the conclusion that discipline does play an independent role in these two aspects or domains of the academic profession.

This is especially evident in two cases. First, both in Europe and outside it, academics belonging to the broad field of science (life sciences, physical sciences, mathematics, computer sciences, and agriculture) are more likely to collaborate with international colleagues in research than their peers belonging to other fields. This finding suggests that academics belonging to disciplines sharing common languages and research programs worldwide, often relying in their work on costly infrastructures (equipment, databases, etc) and long lasting experiments, are more likely to participate in international research networks. Second, at least in the 19 European and nonEuropean countries participating in the CAP Study, academics belonging to the broad field of the medical sciences (together with health-related sciences, and social services) are less likely to have earned a degree abroad, and come back home afterwards, than 
their peers from the other fields. This finding suggests that the peculiar organisational features of a discipline (in terms of the organisation of study programmes, early career, professional regulations, and so on) may hinder international educational circulation. Briefly, international research collaboration and educational circulation may be influenced by the epistemic and organisational traits and practices of each discipline.

In the opposite direction, though, results from data analysis have also pointed out two cases in which disciplines do not play any independent role. First, whether we assume that international research collaboration influences academics' productivity or, vice versa, a positive relationship between international collaboration and productivity has been reported across all disciplines. This finding may be explained in different ways. One possible explanation is that, regardless of discipline, academics exposed to, or involved in, internationally spread practices, institutional arrangements, standards, and policies in terms of work, funding, evaluation, rankings, and publishing tend to behave in a similar way. Second, data analysis shows that shortterm professional circulation does not differ substantially according to discipline. It might be that international travels, visits, exchanges, meetings are so deeply embedded in academic practices and habitus that each academic is expected to spend short periods abroad in her or his regular professional activity, regardless of discipline.

The results reported in the previous paragraphs point out some further differences that deserve our attention. First, the proportion of academics engaged in international research collaboration is remarkably higher in Europe $(62 \%)$ than in nonEuropean countries (34\%), almost twice as much. This huge difference may be associated with the impact of long-lasting research policies designed and implemented by the European Union since the mid-eighties (1984) which have also included other European countries outside the Union - such as Norway and Switzerland through cooperation agreements. ${ }^{12}$ International collaboration in research and technology is a pillar of European policies resulting in a higher proportion of academics collaborating with international colleagues.

Second, academics outside Europe from the broad field of the humanities (teacher training, education sciences, humanities and arts) are less likely to collaborate internationally in research than their peers from other disciplines, while those active in Europe are more likely to collaborate. Here might come into play that European academics active in the humanities might more easily collaborate internationally than their non-European peers, because they often cooperate with academics of neighbouring countries with whom they share a common cultural heritage. But it might also be true that they are keener to collaborate because they have been exposed to the same set of policies as their European colleagues from other disciplines; these policies might have provided effective incentives to address or steer academics' behaviour or at least to encourage attitudes that were already there.

To sum up, we can conclude that depending on the international academic activity under scrutiny, in some cases disciplines play a role resulting in divergent behaviours between academics belonging to different disciplinary fields, while in other cases more powerful forces seem to reduce disciplinary differences, making academics converge to similar behaviours. 


\section{References and Notes}

1. E. A. Höhle and U. Teichler (2013) The academic profession in the light of comparative surveys. In: B. M. Kehm and U. Teichler (eds), The Academic Profession in Europe: New Tasks and New Challenges (Dordrecht: Springer), pp. 23-38.

2. U. Teichler, A. Arimoto and W. K. Cummings (2013) The Changing Academic Profession: Major Findings of a Comparative Survey (Dordrecht: Springer).

3. B. M. Kehm and U. Teichler (eds) (2013) The Academic Profession in Europe: New Tasks and New Challenges (Dordrecht: Springer).

4. U. Teichler and E. A. Höhle (eds) (2013) The Work Situation of the Academic Profession in Europe: Findings of a Survey in Twelve Countries (Dordrecht: Springer).

5. F. Huang, M. Finkelstein and M. Rostan (eds) (2014) The Internationalisation of the Academy: Changes, Realities and Prospects (Dordrecht: Springer).

6. M. Rostan, F. A. Ceravolo and A. Scott Metcalfe (2014) The internationalization of research. In: F. Huang, M. Finkelstein and M. Rostan (eds), The Internationalization of the Academy: Changes, Realities and Prospects (Dordrecht: Springer), pp. 119-143.

7. It might be that a higher productivity enhances international collaboration. We believe that the opposite causal link is more likely - that is, international research collaboration enhances academic productivity - but we acknowledge that we should go deeper into the analysis. What is presented here should be considered as a first step.

8. At least, we can say that international collaboration and research productivity are strongly and positively associated.

9. M. Rostan, and E. A. Höhle (2014) The international mobility of faculty. In: F. Huang, M. Finkelstein and M. Rostan (eds), The Internationalization of the Academy: Changes, Realities and Prospects (Dordrecht: Springer), pp. 79-104.

10. M. Rostan and E. A. Höhle (2014) Crossing the borders: investigating social and economic forces shaping international academic mobility. In: J. Branković et al. (eds), Global Challenges, Local Responses in Higher Education (Rotterdam: Sense Publishers), pp. 63-85.

11. This paragraph refers to the 18 countries and the SAR of Hong Kong which participated in the CAP Study; the five countries participating in the EUROAC Project are not included.

12. A. Gornitzka and L. Langfeldt (eds) (2008) Borderless Knowledge. Understanding the 'New' Internationalisation of Research and Higher Education in Norway (Dordrecht: Springer).

\section{About the Authors}

Michele Rostan is Director of the Centre for Study and Research on Higher Education Systems at the University of Pavia. He is associated professor of Economic sociology at the Department of Social and Political Sciences. He is member of the Consortium of Higher Education Researchers and the Editorial Advisory Boards of the journals Higher Education and Studies in Higher Education. He was responsible for the Changing Academic Profession Survey in Italy and edited the Italian CAP Report (La professione accademica in Italia. Aspetti, problemi e confronti nel contesto 
europeo, 2011). He recently co-edited The Internationalization of the Academy: Changes, Realities and Prospects (2014, with F. Huang and M.J. Finkelstein).

Flavio A. Ceravolo is member of the Centre for Study and Research on Higher Education Systems at the University of Pavia. He is assistant professor of Sociology and Methodology at the Department of Social and Political Sciences. He is member of the Consortium of Higher Education Researchers. Ceravolo's main research interests focus on the relations between education, social stratification and migration. With Michele Rostan, he recently published 'Crossing the borders. Investigating social and economic forces shaping international academic mobility' in the volume Global Challenges, Local Responses in Higher Education (2014). 